\title{
What causes stress incontinence: Fallacies, fascias and facts
}

\author{
John DeLancey, MD \\ Director of Pelvic Floor Research, Department of Obstetrics and Gynecology, University of Michigan, Ann Arbor, MI
}

Cite as: Can Urol Assoc J 2012;6(5):S114-5. htrp://dx.doi.org/10.5489/cuaj.12195

\section{Abstract}

The traditional view of the pathophysiology of stress urinary incontinence (SUI) was that a loss of urethral support was the primary abnormality present. Recent research has challenged this hypothesis, demonstrating that impaired urethral function plays the key causative role. Improving our understanding of the underlying pathologic mechanisms is important to identifying the cause of treatment failures and for developing novel therapies to treat SUI.

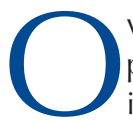
ver the last century, several hypotheses have been proposed to explain the pathophysiology of stress urinary incontinence (SUI). These theories have largely been based on uncontrolled clinical observations or comparing women with stress incontinence to women undergoing urodynamics that did not have stress incontinence (i.e., urge incontinence), focusing on loss of urethral support and an open vesical neck as the primary causative abnormalities. This traditional view of SUI causation has, however, been challenged by recent research investigating the potential role of urethral function in SUI using asymptomatic volunteers for comparison.

\section{ROSE study}

The Research On Stress incontinence Etiology (ROSE) study compared measurements of urethral support and function in women with primary SUI to asymptomatic volunteers. ${ }^{1}$ This was a casecontrol study involving 103 women with SUI and 108 asymptomatic controls matched for age, race, parity and hysterectomy. The key variables analyzed were maximum urethral closure pressure (MUCP), urethral and pelvic organ support, levator ani muscle function, and intravesical pressure.

The study showed that the mean MUCP was $42 \%$ lower among women with primary SUI $\left(40.8 \mathrm{~cm} \mathrm{H}_{2} \mathrm{O}\right.$ vs. $70.2 \mathrm{~cm} \mathrm{H}_{2} \mathrm{O}$; Fig. 1). MUCP was found to be, by far, the strongest predictor of SUI; the effect size (1.47) was substantially higher than that of any other single predictor. In fact, after adjusting for body mass index (BMI), MUCP alone correctly classified $50 \%$ of cases. No measure of urethral support had an effect size greater than 0.6.

\section{Ultrasound investigation}

The investigators of the ROSE study were surprised by their findings that MUCP was the most powerful predictor, with an effect size so much greater than any of the urethral mobility variables assessed in the study. To alleviate concerns that they had not included the correct urethral mobility parameter in their assessments, they subsequently performed a secondary analysis of ultrasound videos of the ROSE subjects' urethral mobility during coughing. ${ }^{2}$ This was carried out by a panel of international experts who were asked to identify which patterns they felt were most likely to be associated with stress incontinence.

The investigators were surprised to discover that none of the experts were able to consistently discern which women were stress incontinent and which were continent based on review of the ultrasounds alone. Indeed, the mean accuracy of these evaluators was $57.4 \%$ (i.e., only $7 \%$ better than the success rate one would expect by random chance). This finding further supports the concept that urethral support is not as important as previously thought.

\section{Investigation of racial differences}

Incidence of incontinence had long been thought to be considerably lower among black women than Caucasian women. Investigators of the Establishing the Prevalence of Incontinence (EPI) study confirmed this fact, finding that only $17 \%$ of black women compared with $34 \%$ of white women reported incontinence. ${ }^{3}$ This study examined the influence of 15 different risk factors for incontinence on racial differences in incontinence rates. Although these predicted incontinence, none of the 15 risk factors explained the racial differences that have been observed.

However, pelvic floor testing of the same cohort showed that MUCP was $22 \%$ higher in black women than in white women (68.0 vs. $55.8 \mathrm{~cm} \mathrm{H}_{2} \mathrm{O}, p<0.0001$; Fig. 2), which translates into less stress incontinence for black women. ${ }^{4}$ To put a $22 \%$ difference into perspective, this is like the height difference between a person who is $5^{\prime} 0^{\prime \prime}$ tall compared to an individual who is $6^{\prime} 1^{\prime \prime}$ tall.

Urethral function has also been identified as potentially important in urge incontinence (UUI) in white women. Data from the EPI study show that white women with UUI had lower urethral pressures compared to continent white women, whereas in black 


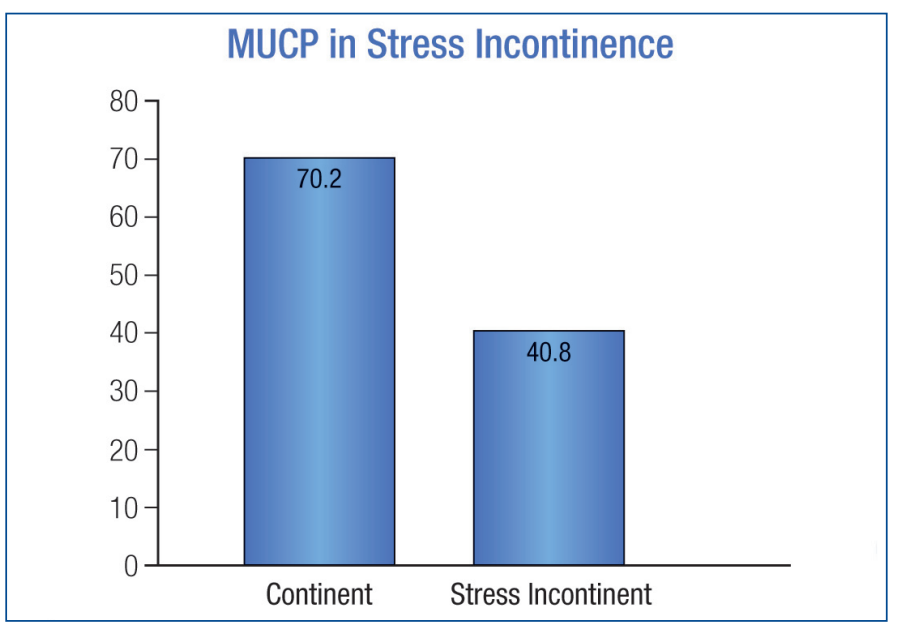

Fig. 1. Maximal urethral closure pressure in stress incontinence versus healthy controls.

women there was no difference in MUCP between continent and incontinent subjects. ${ }^{4}$

\section{What drives changes in MUCP?}

Although the mechanisms behind changes in MUCP are not fully understood, it is known that it declines with age: an approximate $15 \mathrm{~cm} \mathrm{H}_{2} \mathrm{O}$ drop per decade of life. ${ }^{5}$ Aging is also associated with a loss of striatal muscle fibre in the urethra and surrounding tissues. ${ }^{6}$

\section{Implications for treatment}

Although operations that provide differential support to the urethra are effective, urethral support is not the predominant cause of stress incontinence. This has improved our understanding of the small but persistent failure rate of current surgery. Investigators have, for example, identified MUCP as a predictor of failure of midurethral slings. ${ }^{7}$ Furthermore, understanding the factors affecting urethral closure may lead to novel treatments targeting the urethra.

Competing interests: Dr. Delancey has received research support from the National Institutes of Health, Kimberly Clark, AMS, Johnson and Johnson, and Astellas Canada.

\section{Differences in Maximal Urethral Closure Pressure Between Black Women and White Women}

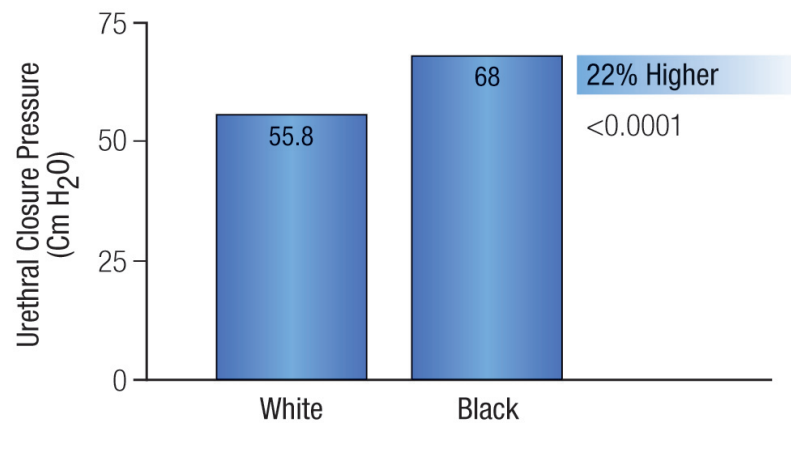

Fig. 2. Differences in maximal urethral closure pressure between black women and white women.

\section{References}

1. DeLancey J0, Trowbridge ER, Miller JM, et al. Stress urinary incontinence: relative importance of urethral support and urethral closure pressure. J Urol 2008;179:2286-90. http://dx.doi.org/10.1016/i. juro.2008.01.098

2. Lewicky-Gaupp C, Blaivas J, Clark A, et al. "The cough game": are there characteristic urethrovesical movement patterns associated with stress incontinence? Int Urogynecol J Pelvic Floor Dysfunct 2009;20:171-5. http://dx.doi.org/10.1007/s00192-008-0738-0

3. Fenner DE, Trowbridge ER, Patel DA, et al. Establishing the prevalence of incontinence study: racial differences in women's patterns of urinary incontinence. J Urol 2008;179:1455-60. http://dx.doi. org/10.1016/i.juro.2007.11.051

4. DeLancey JO, Fenner DE, Guire K, et al. Differences in continence system between community-dwelling black and white women with and without urinary incontinence in the EPI study. Am I Obstet Gynecol 2010;202:584.e1-584.e12.

5. Trowbridge ER, Wei JT, Fenner DE, et al. Effects of aging on lower urinary tract and pelvic floor function in nulliparous women. Obstet Gynecol 2007;109:715-20. http://dx.doi.org/10.1097/01. AOG.0000257074.98122.69

6. Perucchini D, Delancey J0, Ashton-Miller JA, et al. Age effects on urethral striated muscle. II. Anatomic location of muscle loss. Am J Obstet Gynecol 2002;186:356-60. http://dx.doi.org/10.1067/ mob.2002.121090

7. Nager CW, Sirls L, Litman HJ, et al. Baseline urodynamic predictors of treatment failure 1 year after mid urethral sling surgery. J Urol 2011;186:597-603. http://dx.doi.org/10.1016/i.juro.2011.03.105

Correspondence: Dr. John 0. L. DeLancey, Department of Obstetrics and Gynecology, University of Michigan Medical Center, 1500 E. Medical Center Dr, L4000 WH, Box 0276, Ann Arbor, MI 48109-0276; fax: 734-647-9727; delancey@umich.edu 